Norman P. Franke

\title{
Karl Wolfskehls INRI-Zyklus
}

\section{Einleitung}

Karl Wolfskehls "INRI"-Zyklus enthält seine religiösen Anschauungen und Fragen in äußerster Verdichtung. In dem Gedicht ist es ihm gelungen, in 63 Strophen - in eklektischer vor allem aber idiosynkratischer Weise - zentrale Texte der jüdischen und christlichen Überlieferung und des George-Kreises neu zur Geltung zu bringen und in Beziehung zu setzen. Im folgenden können nur Schlüsselpassagen aus dem "INRI"-Text herausgehoben und gedeutet werden, in denen Karl Wolfskehls überragende Kenntnisse von Mythos, Mystik und (Heils-) Geschichte ebenso aufscheinen wie eine gelegentliche Hybridität bei seiner Fusionierung unterschiedlicher religiöser Traditionslinien. Indessen ist "INRI" keinesfalls nur ein gelehrter Text; vielmehr hat er seinen geschichtlichen und soziologischen Ort im Zusammenhang mit einem von Wolfskehl in der Georgeischen "vates"-Tradition erlebten Gotteskampf, einer geistigen - und mindestens aus der Autorperspektive durchaus auch geistlichen - Auseinandersetzung mit neo-paganen Tendenzen in Dichtung und Religion im Deutschland der dreißiger und vierziger Jahre.

Man kann Wolfskehls "INRI"-Zyklus als Station zum "Hiob"Zyklus lesen. Seine entscheidendên thēōlogischen Aussagen über Eschatologie und Messianismus sind im "Hiob" formuliert. "INRI" kann durchaus für sich gelesen werden, aber er komplementiert auch die anderen Gedichtkreise des Wolfskehlschen Spätwerkes. Nimmt man die von Wolfskehl für die Exilwerke benutzte Bezeichnung "Zyklus" ernst und sieht sie im Zusammenhang mit der Poetologie des George-Kreises", so schreitet "INRI" einen geistigen Umkreis aus, dessen Zentrum mit dem des Hiob-Kreises zusammenfällt, auch wenn die "Hiob"-Dichtung die Fragen nach Mensch, Gott und Messias noch einmal auf einer anderen, höheren

1 Der Zyklus ist ein im George-Kreis häufig angewandtes Mittel der Komposition, mit welchem auf der gestalterischen Ebene deutlich gemacht wird, wie zeitlich und personell scheinbar weit auseinanderliegende Dichtungs-Bezüge wesentlich zusammengehören. Topoi, Intertexte, symbolische und formale Beziehungen, welche Gedichtteile oder -gruppen zentrieren oder dynamisieren, können dabei u. a. zur Anwendung kommen. 
Ebene aufnimmt. Progression und Zyklus fallen in der Spiralbewegung von Wolfskehls poetisch-theologischer Komposition des gesamten Exilwerks am Ende zusammen. In diesem Sinne ist "INRI" im "Hiob" aufgehoben. Die Kernaussagen des "INRI" bestehen allerdings neben und mit denen der "Hiob"-Dichtung; innerhalb des Exilwerkes fällt ihnen sogar eine zentrale Stellung zu.

\section{Forschungsbericht}

Im Zentrum der "INRI"-Forschung steht Renate Koch: Sie legte eine kenntnisreiche werkgetreue Rekonstruktion und Interpretation des Zyklus vor ${ }^{2}$ und wies bereits früh auf zwei rezeptionsgeschichtlich bedeutsame Zusammenhänge hin, nämlich erstens auf den Einbezug von Zahlenmystik in die Dichtung - auch auf der Grundlage der gematria ${ }^{3}$ - und zweitens auf die intensive Rezeption der biblischen, genauer: der Thora-Überlieferungen, vor allem der Erzvätergeschichten, die von Wolfskehl wiederholt poetisch paraphrasiert werden. Tatsächlich kommt es - wie Koch bemerkt - im "INRI" wiederholt und an entscheidenen Stellen zu Synopse und Integration von (rekonstruiert) jesuanischer, christlich-theologischer und jüdisch-alttestamentarischer Überlieferung. Doch diesen Zusammenhang deutet Koch automatisch und ohne überzeugende Textbelege anzugeben christozentrisch, als ob etwa z. B. Wolfskehls Affirmierung der Davidischen Sukzession Jesu einzig und allein als Bestätigung christlicher Messianität und im christologischen Schema von (alttestamentarischer) Verheißung und (neutestamentarischer) Erfüllung zu lesen wäre. Kochs christlich-zentrierter Blick wird auch im Hinblick auf die Erwählungsproblematik deutlich: meint sie doch, "INRI ist ein Werk, in dem eine Entscheidung verlangt wird und eine Linie zwischen christlicher Heilsidee und jüdischem Glauben gezogen werden soll."4

2 Koch, Renate, Der deutsch-jüdische Themenkreis im Werk Karl Wolfskehls, Dissertation der George Washington University. o. J.

3 Leider führt sie diesen für Wolfskehls Lyrik so wichtigen mystisch-theologischen und ästhetischen Rezeptionsbezug nicht weiter aus. Wie umfangreich seine Kenntnisse in diesem Bereich waren, ist jedoch anhand des "INRI"-Textes selbst kaum zu rekonstruieren, dazu bedarf es nicht zuletzt des erst vor kurzem edierten Briefwerkes. Bemerkenswert in diesem Kontext ist, daß die jüdischdeutschen Mystiker des 12. und 13. Jahrhunderts, insbesondere aus der Familie Kalonymus, auf die Karl Wolfskehl seine eigene Familiegeschichte zurückführt, die gematria in die kabbalistische Literatur eingeführt und sie dort bleibend etabliert haben. (Vgl. hierzu das "Kabbalah"-Kapitel in: Encyclopedia Judaeica, Jerusalem 1972, S. 516). 
$\mathrm{Zu}$ zeigen wird sein, daß Wolfskehl dem christlichen Entscheidungs- und Erwählungszwang gerade eine Absage erteilt, ohne die besondere Begründung des christlicherseits vorgetragenen Messiasanspruchs im Hinblick auf Jesus zu verwerfen. Gerade weil Wolfskehl Jesus in der Verwurzelung seiner jüdischen Überlieferung anspricht, kann er den messianischen Anspruch auch der christlichen Tradition herausarbeiten und spezifisch christliche, soteriologische und apokalyptische Messiasvorstellungen kritisch würdigen, ohne sie vollständig zu übernehmen.

Vor Renate Koch identifizierte bereits Peter Berglar das lyrische Ich des "INRI"-Zyklus mit "Israel" und kam zu dem Schluß: "Israel vor dem Christus stehend, vor dem Kreuz, unter dem Kreuz. Ich kenne kein Vergleichbares in der deutschen Dichtung - und wir besitzen es - in deutscher Sprache und kennen und wissen es kaum!"5 In den 63 Strophen des "INRI"-Zyklus kommt das Wort "Kreuz" indessen ein einziges mal vor, auch der Begriff "Israel" erscheint nur einmal, allerdings in gänzlich anderem $\mathrm{Zu}$ sammenhang, keinesfalls aber "unter dem Kreuz". Das Wort "Christus" - oder auch adjektivisch "christlich" - erscheint überhaupt nicht im Text! Das "vor und unter dem Kreuz" wird von Berglar offenbar in Anspielung an einen von Wolfskehl verworfenen frühen Titel der Dichtung "Tabula Quaterna quam sculpsit unus ante portam" verstanden. Am Kreuz entschiede sich dann für das lyrische Ich - das natürlich nicht ohne weiteres mit "Israel" ineins gesetzt werden kann - , ob der Zugang zu Christus möglich sei; der portale Zugang wäre dann der Eingang ins christliche Heil. Es steht aber ante portam und nicht juxta crucem, wobei porta, das Tor 6 , in jüdischer Tradition zunächst weniger der Ort eines Passagenritus als der Gerichts- und Verhandlungsort ist; und selbst wenn die christliche Verbindung von Kreuz und Eingang ins Heil tatsächlich auch in Wolfskehls Eigeninterpretation entscheidend sein sollte, warum ist es dann für Berglar so wichtig, darauf zu bestehen, daß diese theologische Deutung sich bei einem Juden in der deutschen Sprache vollzieht?

In seiner Untersuchung von Wolfskehls religiösem Spätwerk blieb Paul Hoffmann vorurteilsfrei, literaturwissenschaftlich und theolo-

4 Renate Koch in ihrer Dissertation, a. a. O., S. 160.

5 Berglar, Peter, Karl Wolfskehl. Symbolgestalt der deutsch-jüdischen Tragödie, Darmstadt 1964, S. 42.

6 Daß dabei möglicherweise auch ein Hinweis auf das letzte Kapitel ("Tor") von Franz Rosenzweigs theologischem Werk Der Stern der Erlösungvorliegt, kann hier nur angedeutet werden. 
gisch genau: Weder identifizierte er das lyrische Ich im "INRI" einseitig mit dem Autor oder mit einem Kollektivbegriff ("Israel") noch meinte er, daß dieses Ich dem als Christus titulierten kirchlichen Heilsanspruch gegenüberstehe; vielmehr konstatierte Hoffmann, daß die "Seele" (Hoffmanns Paraphrase des lyrischen Ich) "die Frage nach der Realität des christlichen Heils [bedrängt]"7. Darüberhinaus macht Paul Hoffmann darauf aufmerksam, daß der "INRI"-Zyklus nicht isoliert betrachtet werden darf, wenn es um die Bestimmung von Wolfskehls Messiasverständnis geht. Daß Wolfskehl mit dem "INRI"-Zyklus eschatologische Grenzgänge vollführt, die sowohl den Ausschließlichkeit beanspruchenden christlichen als auch manchen jüdischen Interpreten ein Ärgernis sein konnten, betonte Hoffmann wiederholt. Er weist in diesem Kontext auf die Gleichrangigkeit der Moses, Jesus und Mohammed Figuren in Wolfskehls Gedicht "Das Gesicht" hin, um die für den Dichter so wichtige gleichzeitige Teilhabe an verschiedenen Interpretationsgemeinschaften innerhalb aller drei historisch eng verwandten monotheistischen Religionsgruppen $\mathrm{zu}$ betonen. ${ }^{8}$ Hoffmann zeigt, daß die Berücksichtigung der Entstehungsgeschichte derjenigen anderen Werke, welche den eschatologischen Themenkreis behandeln, uns wichtige Hinweise auf Wolfskehls Engführung der christlichen und jüdischen Messianik erlaubt, reichen doch die ersten Entwürfe des "INRI"-Zyklus in die Zeit von "Die Stimme spricht" und fallen seine abschließenden Fassungen in die Jahre der Arbeit am "Hiob". Auch gibt Hoffmann bereits einen Hinweis, inwieweit das "Hiob Maschiach"-Gedicht Wolfskehls Spitzensätze in der Frage der Messianik enthält und warum es gegenüber dem "INRI"-Werk letzthin privilegiert erscheint: "... virtuell und relativ [ist] jeder Mensch Mitbereiter des messianischen Reiches. Und keiner, auch nicht der Erleuchteste, erscheint als Quell aller Erlösungsgnade". 9

Die gestalterische Besonderheit des Zyklus als Bibliodrama, in welchem eine menschliche und eine göttliche Stimme ein Wechselgespräch führen, wurde in der Forschung bisher kaum hinreichend berücksichtigt. Denn erstens finden wir im "INRI" ein biblisches Gestaltungsmerkmal vor, das insbesondere im Buch Hiob zur Anwendung kommt und Wolfskehls messianisches Bibliodrama daher wiederum auch auf seine Auseinandersetzung mit der Thora ver-

7 Hoffmann, Paul, Das religiöse Spätwerk Karl Wolfskehls, Maschinenschriftl. Dissertation, Wien 1958, S. 180 (Hervorhebung N.P.F.).

8 Hoffmann, a .a. O., S. 185.

9 Hoffmann, a. a. O., S. 180. 
weist. Zweitens liegt eine direkte strukturelle Parallele zu "Die Stimme spricht" vor, in welcher die göttliche "vox" als diejenige JHWHs bestimmt werden kann. Unabhängig davon, ob in "INRI" eine andere Stimme, nämlich vorrangig Jesu Stimme spräche, oder ob die jesuanische Stimme mit der göttlichen teilweise identisch wäre - die intertextuelle Parallele darf nicht unberücksichtigt bleiben. Sowohl hinsichtlich der jüdisch-christlichen Überlieferungsgeschichte als auch innerhalb von Wolfskehls Gesamtwerk ist "INRI" ein Intertext; die Gesprächskonstellationen und Stimmen aus anderen verwandten Dialogtexten sollten nicht überhört werden.

\section{Zur Entstehung der Tafeln}

Durch sein Interesse an der religiösen Überlieferung des Judentums beschäftigte Wolfskehl sich bereits früh mit Fragen der Eschatologie und der Messianik. Sein mediävistisches Interesse und seine Leidenschaft für Barockliteratur konfrontierten ihn mit christlicher Theologie und Kultur. Eine frühe Vorlesungsmitschrift Wolfskehls, die wohl ein barockes Erbauungslied wiedergibt und Bearbeitungsspuren von Wolfskehls eigener Hand trägt, fand sich jüngst im Deutschen Literaturarchiv in Marbach.10

Das früheste Wolfskehl Gedicht mit dezidiert christlichem Inhalt, das sich kürzlich ebenfalls in Marbach fand"1, sei hier in seiner ersten und letzten Strophe wiedergeben. Es trägt die Überschrift "Gründonnerstag" und wurde vermutlich 1925 geschrieben ${ }^{12}$.

Hast du mich denn verlassen

Ich ruh(t) in deiner Huld (?)

Ich will die Sterne fassen

Wes ist dein Him(m)el ...(?)

$[\ldots]$

Du hast dich losgerissen ....

So fiel ich aus dem Bann

Mein Kleid ist lang zerschlissen

Leer Herz und Blick und Hand

10 Ich möchte an dieser Stelle der Deutschen Schillergesellschaft und dem Deutschen Literaturarchiv in Marbach herzlich für ein Forschungsstipendium zur Erforschung von Wolfskehls Exilwerk im Januar 1998 danken.

11 DLA 85.54.36.

12 Handschriftlich datiert auf dem Gedichtblatt, vermutlich von Wolfskehls eigener Hand. 
Die Parallelen zum späteren "INRI"-Zyklus sind auffällig. Das Gründonnerstag-Gedicht ist ein sehr' frühes Zeugnis für das dialogische Prinzip bei Wolfskehl; hier richtet sich eine Beter-Stimme an einen göttlichen Adressaten. Der Sprachgestus der ersten Strophe und die Tatsache, daß das lyrische Subjekt ohne Antwort bleibt, weisen auf die Dritte Tafel ("R") des "INRI"-Gedichtes voraus.

Zur eigentlichen Entstehungsgeschichte des Zyklus, hier nur eine kurze Liste wichtiger Stationen: Manfred Schlösser zitiert in seinem Katalog zwei Strophen aus dem 9-strophigen Gedicht "Die Acht und das neunte Ja." Er datiert sie auf 1933/34. In dieser Zeit teilweise im Zusammenhang mit den Gedichten der "Stimme" dürfte auch eine dreiteilige Fassung entstanden sein, denn in einem Diarium von 1933/34 findet sich der Titel "Triptychon Christianum". Spätere Fassungen, so die an Pater Michels gesandten, lassen eine Erweiterung von einer "Tabula Triperdita" (ohne Datum) zu einer "Tabula Quaterna/ Quam sculpsit/ Unus ante Portam" (1939 versandt) beobachten. Die Typoskripte besorgte Margot Ruben, sie enstanden also nach November 1934."13

\section{Historische und politische Umstände}

Einen Tag nach dem Reichstagsbrand im Februar 1933 verließ Karl Wolfskehl Deutschland, er ahnte, was die Nazi Herrschaft bedeuten würde.

Wolfskehl ging über die Schweiz ins italienische Exil, dann - kurz bevor auch Ităliēn 1938 āntisèmitische Gesetze einführte - nach Neuseeland, den Europa-fernsten Ort, denn Wolfskehl mußte auf dem Alten Kontinent um sein Leben und sein Werk fürchten; ein "Europa-Ekel" angesichts der Selbstvergessenheit der geistigen Eliten erfüllte ihn.

In einem Gedicht der "Stimme" hatte es im Hinblick auf die traditionsvergessenen Deutschen, insbesondere auch die Christen in Deutschland, geheißen:

Mit unseren Gesängen habt ihr euren Gott gesucht,

Mit unsern Sätzen, Worten habt ihr gesegnet, habt ihr geflucht, Mit unsern dunklen Mären seid ihr gross geworden:

13 Diese Informationen verdanke ich Friedrich Voit, dem an dieser Stelle besonders herzlich für seine freundschaftliche Förderung meiner. Wolfskehl-Forschung gedankt sei! Ohne seine Anregungen und fachliche Hilfe wäre dieser Aufsatz nicht möglich gewesen. 
Die deutsche Kultur wird hier in den Kontext der jüdisch-christlichen Geschichte gestellt; sie basiert wesentlich auf der christlichabendländischen Interpretationsgemeinschaft, die im Alten und Neuen Testament ihre Wurzeln hat. Ihre Narrationen sind ganz überwiegend jüdisches Traditionsgut. Die Bibel ist die entscheidende Grundlage abendländischer Theologie und Literatur. Individuell und kollektiv sind es die sprachlichen Grundlagen, die "Sätze und Worte" des jüdischen Gottesverständnisses, der jüdischen Geschichte mit Gott, mit dem die Deutschen vom Mittelalter über Luther bis in die Neuzeit aufwuchsen, an denen sie sich zu einer Kulturnation bildeten und die sie zu geistigen Rezeptions- und Eigenleistungen anregten, mit denen sie dann selbst berühmt ("groß") wurden. Die deutsche Sprachschöpfung Luthers findet in biblischer Sprache, in ihrer Anschaulich- und Gedanklichkeit, statt. Doch biblische Sprache war im deutschsprachigen Raum nicht allein geschichts- und identitätsstiftendes Medium, sie war darüberhinaus auch sakramentale Sprache ("Mit unsern...Worten habt ihr gesegnet..."). So muß Karl Wolfskehl in Anbetracht des von den Nazis proklamierten "nordisch-germanischen" Tausendjährigen Reiches wehmüig von dem Abschied eines anderen tausend Jahre währenden Reiches, dem der jüdisch-deutschen Gemeinsamkeit, sprechen:

Tausend Jahre huben an und enden in unserer Weise,

Tausend Jahre zerrannen und wenden sich leise 15

Speziell für die an "nordischer Religion" und an einer Identifizierung von griechischer Antike und deutschem Neu-Heidentum interessierten Mitglieder des George-Kreises schrieb Karl Wolfskehl die folgenden Passagen seinem "Lebenslied, An die Deutschen" ein:

Dein Weg ist nicht mehr der meine,

Teut, dir schwant, erkoren seist

Du am Nordgrat, nicht am Rheine,

Lug sei, was dich Andern eine,

Lug das Lamm in Kreuzespeine,

Blut sei Same, Gift der Geist.

14 GW I, S. 158.

15 GW I, S. 158. 
Borgst dir Zeichen, Zucht und Richter,

Löschest aus die eignen Lichter,

Fährst vom Weltentempelhaus

Deiner Kaiser, deiner Dichter

Brüllend, Teut, ins Dunkel aus:

Wüsstest du was drinnen kreist!

Nacht hat auch zu mir gesprochen,

Gottesnacht, schwer dröhnt das Wort:

Losgebrochen! Losgebrochen!16

"Teut" ist das Eponym für jene Anhänger des Georgeischen Geheimen Deutschland, welche dieses aus seiner christlich-mittelalterlichen Tradition herauslösen wollten. So wịd das Lamm Gottes hier mit einer Deutungstradition Georgeischer Reichsmystik konfrontiert, die allein auf den Bezug der deutschen mittelalterlichen Kaiserreiche zur römischen Antike abhob. Aber auch die literarische Geschichte wurde von Wolfskehl auf Antizipationen dieses Traditionsbruches untersucht. So hieß es 1936 in einem Brief an Edgar Salin:

Die Heinesche Vision hab ich inzwischen gelesen und wie Sie mit Staunen und sehr ergriffen. Das Unheimlichste ist die Wendung gegen Westen und die Ahnung wotanischen Losstürmens, der prächristianischen ... Krustensprengung. ${ }^{17}$

Heinrich Heine hatte geschrieben:

[...] und wenn einst der zähmende Talisman, das Kreuz, zerbricht, dann rasselt empor die Wildheit der alten Kämpfer, die unsinnige Berserkerwut, wovon die nordischen Dichter so viel singen und sagen. Die alten steinernen Götter erheben sich dann aus dem verschollenen Schutt, und reiben sich den tausendjährigen Staub aus den Augen, und Thor mit dem Riesenhammer springt endlich empor und zerschlägt die gotischen Dome. Wenn Ihr dann das Gepolter und Geklirre hört, hütet Euch, ihr Nachbarkinder, Ihr Franzosen $[\ldots]^{18}$

In seinem "Lebenslied" findet sich zum ersten Mal bei Wolfskehl

16 GW I, S. 219.

17 BaI, S. 195.

18 Im III. Buch der Geschichte der Religion und Philosophie in Deutschland (Heinrich Heine, Sämtliche Weke [Hrsg. H. Kaufmann], Bd. IX. München 1964. S. 283. 
- und in der Dichtung des George-Kreises - der Hinweis auf die christliche Lamm-Gottes-Tradition, die hier mit dem "Weltentempelhaus" der deutschen Kaiser und Dichter verbunden wird. Unter dem Schock der politischen Ereignisse in Deutschland modifiziert Wolfskehl damit das heroische antike und mittelalterliche Geschichtsbild des Kreises und verweist warnend auf die Auserwähltheitsphantasien jener George-Deutschen, die meinten auf die jüisch-christliche Tradition des zum Leiden erwählten Gottesknechts gänzlich verzichten zu können.

Cornelia Blasberg gibt einen sozio-psychologischen Grund für die Entstehung von Wolfskehls religiöser Exillyrik an. So sieht sie die göttliche "vox" in der "Stimme" als Mittel an, einen "sprachmagisch evozierten Raum universeller Verständigung" zu schaffen, der - hier bemüht sie ein Wort Georg Lukacs' - einen Rückweg aus der "transzendentalen Obdachlosigkeit der Moderne" ermöglichen solle.19 Blasberg erklärt die psychologische Dynamik hinter dieser Ästhetik des Transzendentalen als eine projektive, da sich "die Fragen der Gedichte dem Suchenden... zu individuellen Antworten verwandeln."20

Wenn Blasberg meint, daß die Stimmführung der "Stimme" deshalb keinen Anspruch erhebe, "religiös zu sein", weil sie nicht in eine kultische oder dogmatische Rede verfällt oder eine Ritusgemeinschaft herbeizuführen sucht, so ist ihr gewiß zuzustimmen. Andererseits ist zu fragen, ob der poetische Versuch, mit einer göttlichen Stimme - und wichtiger vielleicht noch: über eine göttliche Stimme - in einen Austausch über die letzten Dinge einzutreten, und daraus möglicherweise āüch Handlungsanweisungen für das Leben im Exil zu beziehen, nicht selbst eine religiöse Dimension hat. $\mathrm{Ob}$ hierin nicht gerade eine der entscheidenden Stärken der jüdischen religiösen Tradition, die Wolfskehl in der "Stimme" ebenso wie im "INRI" erneut zur Sprache bringen will, besteht. Denn wie vorteilhaft unterscheidet sich die offene, mitteilsame Dialogizität mit und über Gott und Messias in der "Stimme" und im "INRI" etwa von den kultischen Überlieferungen des Georgeischen Maximin-Kults, die viel apodiktischer und zwanghafter gegen die Entzauberung und Entmythologisierung der Moderne in Stellung gebracht werden. Der Raum "universeller Verständi-

19 Blasberg, Cornelia im Nachwort des von ihr herausgegebenen Briefwechsel von Wolfskehls aus Italien. In: BaI., S. 438.

20 BaI S. 438: Es ist hier nicht ganz eindeutig, ob sie dieses für den Autor und/ oder den Leser aussagt. Ich beziehe mich im folgenden vor allem auf die Lesart, das dies dem Autor gilt. 
gung" ist bei Wolfskehl ganz ernst zu nehmen: als kommunikativer - und auch kosmischer - Raum menschlichen Sprechens, der jedoch, wie wir im "INRI" erfahren, aus der göttlichen Geschichte und Kosmogenese selber hervorgeht und - wie Wolfskehl uns zunächst im "INRI" und später im "Hiob Maschiach" zeigt im $\mathrm{Du}$, im Gegenüber des leidenden Gottesknechtes seine ontologische wie moralische Letztbegründung hat.

\section{Zur Rezeption jüdischer und christlicher Theologie}

Man darf davon ausgehen, daß Wolfskehl die gesamte einschlägige jüdische Literatur seiner Zeit zur Leben-Jesus-Forschung und Messianität gekannt hat.21 Als religions- und mythengeschichtlich Interessierter, als einer der Mitbegründer der Münchner Zionisten Gruppe und als Altphilologe hatte er die besten Voraussetzungen, den Diskursen der jüdischen Theologie zu folgen und an ihnen teilzunehmen. Die jüdische Leben-Jesu-Forschung hat in der "INRI"-Dichtung erhebliche Spuren im Detail hinterlassen.22 Entscheidend war für Wolfskehl allerdings die Einbettung des geschichtlichen Jesus in die jüdische Überlieferung an sich.

Der George-Tradition folgend interessierte Wolfskehl die empiri-

21 Die religionsgeschichtliche Literatur von Leo Baeck (Die Pharisaer, 1934), Robert Eisler (Iesus basileus ou basileusas, Heidelberg 1929/1930), Joseph Klausner (Jesus von Nazareth, Berlin 1934) Emil Ludwig (Der Menschensohn, Berlin 1928) darf man bei Wolfskehl wohl als bekannt voraussetzen. Zeitzeugen und Wolfskehlinterpreten haben wiederholt auf den weiten kulturgeschichtlichen Horizont des Dichters hingewiesen, der mit großer Wahrscheinličkēeit àuch seine zeitgenössischen Standardwerke der jüdischen Leben-Jesu-Forschung umfaßte. Eine ausführliche Untersuchung einer Rezeption der genannten Titel bleibt ein Forschungsdesiderat; die nachfolgende Fußnote mag demonstrieren, inwieweit Wolfskehl etwa das Standardwerk Güdemanns rezipiert haben könnte.

22 Anregungen zu den Urmythen in der Ersten Tafel könnte Wolfskehl etwa durch die Lektüre von Moritz Güdemann (Religionsgeschichtliche Studien, Leipzig 1876) erhalten haben. So die Stelle, wo der "Vogel ohne Geburt aus dem Ei" erscheint; hier mag neben der griechischen Mythologie auch Güdemanns Parallelisierung mit jüdischer und christlicher Überlieferung wichtig sein (vor allem im Kapitel 'Der Vogel Phönix, das Symbol der 'Auferstehung' und 'unbefleckten Empfängnis"'). Man beachte Güdemanns Anführungszeichen; die christliche Auferstehung spielt weder bei Güdemann noch in Wolfskehls "INRI" eine entscheidende theologische Rolle.

Daniel Chwolson diskutiert in seinem Buch Das letzte Passahmahl Christi und der Tag seines Todes. Nach den in Übereinstimmung gebrachten Berichten der Synoptiker und des Evangelium Johannis (Leipzig 1908, S. 189) ausführlich das Verhör Jesu durch Pilatus; dieser Text mag Wolfskehls Zweite "INRI" Tafel beeinflußt haben. 
sche Jesus-Figur daher letzlich weniger als die geschichtliche und sinnbildliche Gestalt. Insgesamt ist seine (Neu-) Interpretation der Verankerung der christlichen Überlieferung in der jüdischen Tradition nicht ohne die jüdische Religionswissenschaft um die Jahrhundertwende zu denken. In einer Schlüsselstelle der Zweiten Tafel heißt es:

BIST DU Davids Reis und stehest in

Unserem Buch mitten drin?

- Dir tagt es. Ich Bins. - 23

Dieser Passus ist vornehmlich mythologisch und überlieferungsgeschichtlich, aber durchaus auch historisch-kritisch zu verstehen.

Insbesondere die Bedeutung von Martin Bubers Ich-Du-Dialogizität für Wolfskehls religiöse Exildichtung kann nicht genug betont werden. Als Gestaltungsprinzip, im Gespräch zwischen einer menschlichen Stimme und ihrem göttlichen Gegenüber in Form einer "vox", findet sie sowohl in der "Stimme" als auch im "INRI" und im "Hiob" Verwendung. In einem offenen Brief an den protestantischen Theologen Gerhard Kittel vom Juli 1933 hatte Buber das Gesamt der (Heils-)Geschichte als Gottes Gespräch mit der Menschheit bestimmt:

Geschichte ist keine Thronrede Gottes, sondern sein Ge spräch mit der Menschheit. Wer nicht alles verfehlen will, muß darauf bedacht sein, die Stimmen der Partner zu unter scheiden. ${ }^{24}$

Dieses Wort von Buber könnte geradezu als Motto des "INRI" stehen.

Auch die Rezeption von Franz Rosenzweigs Werk, vor allem seines "Stern der Erlösung", hat den "INRI"-Zyklus mitgeprägt. Hervorzuheben ist hier vor allem Rosenzweigs Kritik einer theologischen Idealisierung Christi, die ihn aus seinen lebenswirklichen Bezügen löst und damit wirklichkeitsfremd und ideologieanfällig macht. Eine Rosenzweigsche Schlüsselpassage im Zusammenhang mit dem "INRI" lautet:

Ob Christus mehr ist als eine Idee - kein Christ kann es wissen. Aber daß Israel mehr ist als eine Idee, das weiß er,

23 GW I, S. 195.

24 In: Buber, Martin, Die Stunde und die Erkenntnis. Reden und Aufsätze, Berlin 1934, S. 176. 
das sieht er. Denn wir leben. Wir sind ewig, nicht wie eine Idee ewig sein mag, sondern wir sind es, wenn wirs sind, in voller Wirklichkeit. 25

Die Betonung des hier gleichermaßen ontologisch wie geschichtlich-transzendent gebrauchten Verbes "sein" ("Wir sind ewig, wir sind es, wenn wirs sind") findet sich in der auf den hebräischen Gottesnamen anspielenden Schlußzeile der Zweiten Tafel im "INRI", aber auch in der Vierten, in dem auf Israels fortgesetztes historisches Sein als fundamentalem Bestandteil göttlicher Heilswirklichkeit - und als Komplement zur christlichen Eschatologie aufmerksam gemacht wird.

Auch hinsichtlich der christlichen Theologie muß man davon ausgehen, daß Wolfskehl die zeitgenössischen Autoritäten kannte, zum Teil sogar persönlich kannte. Mit einem der größten christlichen Leben-Jesu-Forscher seiner Zeit, mit Albert Schweitzer, war er bekannt. In einem Widmungsgedicht auf Schweitzer aus dem Jahr 1932 heißt die Schlußstrophe, die in dem Geist- und Äonenhymnus am Ende der Zweiten "INRI" Tafel ein Echo hat:

\section{Du Geist von Günsbach, dich zu spüren \\ Welch Seinsgewinn! \\ Du sollst mich meine Strasse führen \\ So wie ich selber bin!26}

Bultmanns bahnbrechende Jesus Monographie von 1926 gehörte zum selbstverständlichen Wissen der theologisch Interessierten seiner Zeit. Allerdings war Wolfskehls nicht wie Bultmann an der jesuanischen Theologie selbst interessiert; mit Bultmann könnte die Entmythologisierung Jesu jedoch für Wolfskehl vor allem eine Frage an das eigene Messias- und Auferstehungsverständnis gewesen sein, die im "INRI" im Sinne von Rosenzweig beschieden wird. Eine persönliche Freundschaft verband Karl Wolfskehl mit Pater Thomas Michels OSB, dem auch ein Widmungsxemplar des "INRI"-Zyklus zuging (DLA 75.296/1)27. Michels war kein systematischer Theologe, sondern vor allem Kirchengeschichtler. Anregungen von ihm kamen Wolfskehl hauptsächlich aus Gesprächen. Michels Beziehung zu Wolfskehl war aber nicht nur durch

25 Rosenzweig, Franz, Der Stern der Erlösung, Frankfurt a. M. 1993, S. 461.

26 GW I, S. 263.

27 Die Widmung lautet: "Dem von Herzen verehrten Herrn Thomas Michels O.S B. in Dankbarkeit und Freundschaft. Karl Wolfskehl". 
theologische Dialogizität gekennzeichnet, sondern teils auch seelsorgerlicher Art. Das bezeugt der Briefwechsel. So heißt es in Wolfskehls Brief vom 19. IX. 1938 u. a.:

Lieber, verehrter Pater Thomas,

Eine unausprechliche Freude hatte ich mit Ihrem Brief, sie dauert fort. Ihren Zeilen entströmt sie wirklich, die himmlische vox! Und etwas von ihr flutet in mich, der ich einsam und doch mit dem fürchterlichen Geschehen in der Heimat verbunden ... (bin).

Sie wissen um mein Ringen, Pater Thomas! Und wir Europäer, nun da und dort gelandet, in immer nur notdürftig gezimmerter Seelenhausung untergekrochen, wir müssen ausharren, es geht um die Erhaltung, die Sicherung eines vieltausendjährigen Kontinuums... das heute des göttlichen Schutzes befürftiger (ist) als irgendwann, freilich auch gewiß.

[...]

Sie kennen die Tabula, sie ist eine Quaterna geworden mir selber zum staunenden Schreck, und die Lösung ist immer noch weit in der Ferne. Dies 4. Gedicht kann ich Ihnen noch nicht darreichen, es ist von diesen letzten Tagen hier noch zu herznah - ich gebe es nächstens.

[...]

Schreiben sie mir wieder, Pater Thomas, ich habe viel Festigung davon! Ich bin in Verehrung und Freundschaft der Ihre

Karl Wolfskehl. ${ }^{28}$

Das freundschaftliche Verhältnis zu Michels wird hier ebenso deutlich, wie die Tatsache, daß der Benediktiner als ein Sprachrohr der Gottheit aufgefaßt wird. Die göttliche "vox" des Gedichts verdankt Pater Michels also wichtige Impulse. Was Wolfskehl mit der "Lösung", die immer noch in weiter Ferne stehe, meint, ist nicht vollständig klar. Es ist vermutet worden, daß sie zusammen mit dem "Ringen" einen Hinweis auf mögliche Konvertierungsgedanken Wolfskehls ausdrückt. Bedenkt man jedoch Wolfskehls feste Verankerung im Judentum und in der Weltanschauung Georges, so ist dies unwahrscheinlich. Viel naheliegender ist, daß Wolfskehl hier das Ringen darum ausspricht, wie er seine jüdischen und christlichen Vorstellungen hinsichtlich der Bedeutung Jesu und der Messianik im "INRI" zusammenfügen kann. Die Vierte Gedichttafel im "INRI" und der "Hiob"-Zyklus sind Wolfskehls auto-

$28 \mathrm{BaN}$ II, S. 278. 
ritatives Wort hierzu, weshalb der Hinweis auf die "Quaterna" nicht nur ein editionsgeschichtlicher ist. Wichtig im Brief ist aber auch der erneute Verweis auf die gemeinsame vieltausendjährige jüdisch-christliche Kultur- und Glaubensgeschichte, deren Bewahrung Juden und Christen gleichermaßen aufgetragen ist.

Einen Hinweis auf christlich-zentrierte abendländische Ökumene findet man in Michels Übersetzung eines Christus-Hymnos von Clemens von Alexandria. ${ }^{29}$ Andere eventuelle Anregungen Michels für Wolfskehls "INRI"-Dichtung lassen sich z. Zt nicht nachweisen.

\section{Einflüisse des George-Kreises}

Obwohl alle George-Biographen aus seinem Kreis auf die besondere Bedeutung der katholischen Religion für die frühe Sozialisation des Dichters verweisen und in jüngster Zeit von Braungart zurecht daran erinnert worden ist, $\mathrm{da} \beta$ George sich bei der Formation seiner weltanschaulichen Gemeinschaft und ihres Kultes ausgiebig bei den Traditionen des Katholizismus bedient hat ${ }^{30}$, hatte die Rezeption christlicher - und vor allem jüdischer - Literatur im George-Kreis nur einen untergeordneten Stellenwert.

Seit der Jahrhundertwende stand jüdische Religiosität im Kreis um George in Anschluß an Nietzsches Religionskritik im Verdacht, ein metaphysisches "Gott-Gespenst" zu propagieren; die griechischrömische Antike wurde generell gegen die jüdisch-christliche Tradition ausgespielt. Zwar konzedierte George im Vorspiel zum "Teppich des Lebens", daß das "kreuz" noch lange Zeit das "licht der erde" für die "menge", die unprofilierte, resentiment-

29 Michels übersetzte u. a.:

Lieder, lautere,

Lieder, untrügende,

Dem König Christos,

Heilig Entgelt für

Die Lehre des Lebens,

Singen im Bund wir,

Singen einfältig

Den Sohn, ja den mächtigen

Reigen des Friedens,

Die Christosentsprossenen,

Volk, verständiges,

Singen im Bund wir den Gott des Friedens.

$30 \mathrm{Vgl}$. Braungart, Wolfgang, Ästhetischer Katholizismus. Stefan Georges Rituale der Literatur, Tübingen 1997. 
volle Masse der Menschen bleiben werde. Der George-Kreis, der sich gleichermaßen als politische Elite und als eine religiöse Schar Auserwählter verstand, wollte indessen eine neue Mythologie realisieren:

Eine kleine schaar zieht stille bahnen

Stolz entfernt vom wirkenden getriebe

Und als losung steht auf ihren fahnen:

Hellas ewig unsre liebe ${ }^{31}$.

Vor allem im "Templer"-Gedicht des "Siebenten Ringes" wird jedoch Georges griechisches Ideal des schönen Leibes und eines erotischen Männer- und Heldenbundes auf eigenwillige Weise mit der christlichen Tradition der Johanneischen Logos/Sarx-Theologie verbunden. Naturreligiöse Auffassungen reproduktionsbiologischer Schöpfung im Zeichen der "Großen Mutter" will George hier mit seinem gewalttätig-männlichen Geist-Prinzip überbieten:

\section{(...)}

Und wenn die grosse Nährerin im zorne

Nicht mehr sich mischend neigt am untern borne.

In einer weltnacht starr und müde pocht:

So kann nur einer der sie stets befocht

Und zwang und nie verfuhr nach ihrem rechte

Die hand ihr pressen. packen ihre flechte

Dass sie ihr werk willfährig wieder treibt:

Den leib vergottet und den gott verleibt ${ }^{32}$

Georges eigenen poetischen Äußerungen - ebenso wie die anderer Kreismitglieder - über Jesus Christus sind im "INRI" kaum erkennbar. Im "Gespräch des Herrn mit dem römischen Hauptmann" wird ein heldisches Christusbild geliefert, in dessen "Herrenworten" unschwer Georges eigene Vorstellungen über heroische Eschatolgie zu erkennen sind. Solchem von Hölderlin her bekannten Christus-Herakles gesellt sich bei anderen Georgianer wie etwa Johann Anton ein "apollinischer".33 Von alledem existiert in

31 SW, Bd. V., Stuttgart 1984, S. 16.

32 SW, Bd. VI/VII., Stuttgart 1984, S. 52

33 So heißt es in Antons bezeichnenderweise "Michelangelo" überschriebenen Gedicht (in: Anton, Johann, Dichtungen. Verlag der Blätter für die Kunst, Berlin 1935, S. 21):

(...)

Herr. hast du so die frommen dir verpflichtet 
Wolfskehls "INRI" kaum eine Spur. Der heroische Christus wird bei ihm zugunsten einer in jüdischer Tradition stehenden jesuanischen Messiasgestalt zurückgenommen; dem erhabenen Christus wird erstmals der Gottesknecht aus Jesaja 53 an die Seite gestellt. $\mathrm{Daß}$ der "INRI"-Zyklus zu Wolfskehls Lebenszeiten nicht veröffentlicht wurde, wird neben praktischen Schwierigkeiten auch daran gelegen haben, daß der Exilant nach den Irritationen und Kämpfen im Zusammenhang mit der Veröffentlichung der "Stimme" sich mit dem "INRI" bei den Hellas-orientierten George-Anhängern nicht noch größeren Mißverständnissen und Anfeindungen aussetzen wollte.

\section{Zur Interpretation der "INRI"-Tafeln}

\subsection{Zum Gesamtaufbau des Zyklus}

Verallgemeinernd kann gesagt werden, daß die vier Tafeln des "INRI"-Zyklus mit welt- und religionsgeschichtlichen Epochen korrespondieren:

Tafel "I" Urzeit

Tafel "N" Jüdisch-christliche Zeit

Tafel "R" Neuzeitliches Christentum

Tafel "I" Jüdisch-christliche Endzeit, Juden- und Christentum der Zukunft, Apokalypse

Der zyklischen Anlage der Dichtung entsprechend ändert sich die Stimme von Wolfskehls menschlichem Gedichtsubjekt im "INRI"Zyklus ebenso wie die göttliche Antwortstimme, ohne daß sie dadurch jeweils völlig andere würden. Die menschliche Stimme kann individuell (Erste und Dritte Tafel) und kollektiv (Zweite und Vierte Tafel) verstanden werden, zuweilen trägt sie deutlich biographische Züge des Autors (in den beiden letzten Tafeln). Die Gottesstimme nimmt germanische (Erste Tafel), jahwistische, jesuanische und Georgeische (Zweite Tafel und Vierte Tafel) Elemente

Wie mich der schönen auge bannend schlägt?

Hat dies der tausend-jahre sinn gerichtet

Auf dich der aller schönheit schönste trägt?

Ich kann dich. Herr. nur so erkennen: keiner

Hat übers grab. das alle stumm vergisst

den schönen leib gerettet - nur du Reiner

Bist uns gewähr dass schönheit ewig ist 
auf. Dennoch sind vox humana und vox divina insgesamt kohärent konzipiert.

Bestimmte stoffliche Motive wie das des Gottesknechts wiederholen sich in abgewandelter Form in den verschiedenen Tafeln; der Gottesknecht begegnet etwa in der ersten Strophe der Ersten Tafel, der vierten Strophe der Zweiten und der ersten Strophe der Dritten Tafel. Vor allem in der Zweiten Tafel werden alttestamentarische und jesuanisch-neutestamentarische, teilweise dezidiert christliche Theologeme zusammengebracht. Entwicklung, Wiederholung und Verschränkung von Motivkreisen erinnern an die musikalische Kompositionsform der Fuge. So kann man die Schlußverse der Zweiten Tafel, die in der Mitte des Gedichts stehen, als Engführung sämtlicher Elemente der Gotteslehre in Wolfskehls "INRI" begreifen. Sieht man die Stellung der Engführung achsensymmetrisch, wäre der "INRI"-Zyklus in Analogie zu einer Spiegelfuge gebildet. Folgt man dem Kommentator der Wolfskehlschen Werkausgabe und sieht den Mittelmeer-, den "INRI"- und den "Hiob"Zyklus als zusammengehörig an, steht die theologische Engführung des "INRI" auch im achssymmetrischen Zentrum dieser drei Zyklen insgesamt.

Schließlich bildet die heilsgeschichtliche Periodizierung der Tafeln die Möglichkeit, den "INRI" gleichsam als poetisch-logarithmischen Nachvollzug ${ }^{34}$ des göttlichen Geschichtsdialoges zu erfahren. Anders als bei George unterliegt der progressiven Heilsgeschichte und der zyklisch-typologischen Geschichte im "INRI" nicht nur ein (mythologischer) Raum-Zeitlicher Rahmen, sondern in ihm verwirklicht sich unmittelbar göttliches Heilsgeschehen. In Wolfskehls "INRI" steht Gott in und außerhalb der Geschichte. Er hat metaphysische Aspekte. Bei George verwirklicht sich das Göttliche rein im Leiblich-Menschlichen. So überwindet Wolfskehl die Georgeische Theologie: sein Gott bleibt personhaft ansprechbar, partiell metaphysisch, er bleibt das Gegenüber, unplanbar, unvereinnahmbar 35 - und dennoch dem Gebet, dem fragenden und rin-

34 Mit dieser Beschreibung bemühe ich sowohl die Ethymologie des Wortes als auch dessen mathematische Bedeutung. Demnach wäre der INRI-Zyklus gleichsam ein regelgeleitet abstrahierter Exponent jener göttlichen Sprach- und Dichtungsgeschichte, der das Gesamt kosmologișchen und realgeschichtlichen Geschehens aufnimmt und in seiner gesteigerten - heilgeschichtlichen - Bedeutung widergibt.

35 Der nicht verfügbare Gott der Geschichte erinnert freilich an die Dialektische Theologie; ob Wolfskehl die Werke etwa Karl Barths gekannt hat, ist jedoch nicht zu ermitteln. 
genden Anruf zugewandt.

\subsection{Erste Tafel "I"}

Anders als bei der "Stimme" setzt der Dialog im "INRI" seitens der göttlichen "vox" ein. Die dreimalige Frageansprache "Weißt du..." kann als Anspielung an altgermanische Mythologie gelesen werden, so an das Frageorakel des gehenkten Odin in der Weltesche Yggdrasil aus der Edda. Daß es um mythisches Urgeschehen geht, in welchem jedoch von Anfang an die Messiasfrage nach dem "verhöhnten König" gestellt wird, erscheint in traditioneller judeo-christlicher Geschichtssicht, in der die Genesis den heilsgeschichtlichen Bericht eröffnet, zunächst ungewöhnlich und doch ist sie für Wolfskehls mythopoetisches Denken fundamental. Denn so steht der messianische Gottesknecht, der sowohl in den folgenden Tafeln als auch später in Wolfskehls "Hiob"-Zyklus gestaltet wird, in einem kosmologischen Zusammenhang. Dieser muß nicht unbedingt in paulinisch-christlicher Weise als heilsgeschichtliche Teleologie begriffen werden; gleichwohl teilt er mit der christlichen Überlieferung den Gedanken, daß das Messiasgeschehen schon in Zeit- und Seinsbereichen beschlossen liegt, welche dem Anbeginn der (empirischen) Welt vorausgehen. Der Messias ist also ein prääonischer und prä-mundaner, der allerdings - wie erst im "HiobMaschiach" voll erkennbar wird - je und je in der Zeit seine Wirkung entfalten und sich neu personifizieren kann. Im "INRI" geht es mithin dialogisch um das Schicksal des gemarterten Königs, des leidenden Gottesknechts, des Ebed JHWH, der allen Welten und allem Verstand vorausliegt. 36

Erst in der vierten Strophe, die in christlicher und jüdischer Zahlensymbolik gleichermaßen bedeutsam ist, setzt die Antwortstimme des lyrischen Ich ein. Dies ist signifikanterweise auch die Strophe, in der nach dem Ursprungsort des Lichts gefragt wird. Wenigstens dreierlei Allusionen scheinen hier möglich: Eine an die Lichtschöpfung nach dem Genesis-Bericht, eine an den Logos-Hymnos des Johannesevangelisten sowie eine, welche auf neo-platonische Lichtmystik abhebt. In jedem Fall ist das ur-mythische Gedicht-

36 Die Präexistenz des Messias könnte Wolfskehl dem apokryphen Ennoch Buch (En 62,7) entlehnt haben. Zu rabbinischen Traditionen, welche eine Präexistenz zentraler Größen jüdischer religiöser Anschauung (Thora, Garten Eden, Gehenna, Thron, Tempel) annehmen, vgl. Frederiksen, Paula, From Jesus To Christ. The Origins of the New Testament Images of Jesus, New Haven und London, 1988, S. 81. 
subjekt zunächst gegenüber den Fragen der (göttlichen) "vox" ignorant "Weisst du wo wohne Saug-Amme des Lichts? - Von allem und allem und allem nichts! -") Von der Ahnung ("- Ich ahns, ich ahns! -") , über das Lernen (“ - Ich lern, ich lern! -”) bis zur Entflammung (" - Ich flamm, ich flamm! -") und zum Wissen (“ - Ich weiss, ich weiss!") entwickelt sich der religiöse Horizont der vox humana mit den Fragen bis hin zur Einsicht in das Mysterium christlicher Trinität und des Pantokrators.

\subsection{Zweite Tafel "N"}

Die drei ersten Fragen dieser Tafel, welche auf das Involviertsein des angesprochenen göttlichen Messias in die mythologischen Urberichte des biblischen Genesis-Buches (Paradiesbericht, Kains Brudermord, Sintflut) abzielen, werden direkt und positiv, wenn auch im Präteritum beantwortet ("- Du fragst es. Ich wars. - "). Hervorzuheben ist hier wie auch in den folgenden Strophen, daß die befragte Gottesstimme nicht nur symbolisch oder metaphysisch in den zitierten Geschichten der Thora vorkommt, sondern daß von ihrer "tatsächlichen" Anwesenheit ausgegangen wird. Der göttliche Ansprechpartner war nicht wie oder durch Noahs Taube in der Urgeschichte aktiv, sondern er war Noahs Taube. Es geht hier also um mehr als um einen alttestamentarischen Schriftverweis, um mehr als literarisch-prophetische oder topologische Präfiguration des messianischen Heils - es geht um die Frage nach der währenden ontologischen Präsens des Messianischen (des Messias) in der Geschichte. Für den "INRI"-Dichter war und ist der Messias auch jenseits des jesuanischen Geschehens und seiner Überlieferung in den Evangelien und seiner Theologisierung durch Paulus immer schon dagewesen. Er ist bereits der biblischen Urgeschichte eingeschrieben und mehr noch: er ist in ihr partiell realisiert.

Die Fragen, welche auf die biblischen Erzvätergeschichten und zugleich dezidiert auf christologische Zusammenhänge verweisen (so in Strophe vier: "BIST DU das Lamm...?") werden signifikanterweise anders erwidert, nämlich mit der Wendung : “- Du sagst es. Ich bins. -" Der messianische Gott des Alten und Neuen Testaments wird hier erkennbar, als einer, der sich auf die jüdischbiblische Geschichte ganz eingelassen hat. Er ist das Opferlamm, das Abraham an Isaaks Statt opfert, er ist das Lamm Gottes, das zur Erlösung für viele geopfert wird (Joh. 1, 29; Apokalypse 5,12). $\mathrm{Daß}$ das "Ich war" dieses Gottes sich gerade in der AbrahamsStrophe zu dem "Ich bins" wandelt, ist bezeichnend. Denn die 
Abrahamitische Geschichte ist diejenige in der Bibel, in der Gott sich ganz dem Leben des Erzvaters wie der Hebräer als Volk verbindet. Abraham ist die erste biblische Gestalt, mit der Gott einen fortgesetzten Dialog aufnimmt, der über die Generationenfolge auf das Eschaton der Geschichte, das Gelobte Land, verweist. Der Stammesgott wird in dieser Überlieferung als dialogischer Gott zum Geschichtsgott. So tritt er in seiner Beziehung zu Abraham, dem Stamm der Hebräer, und später der jüdisch-christlichen eschatologischen Tradition als Ansprechpartner in die Geschichte ein. Er ist seitdem an der Seite seines Volkes.

Aber das göttliche " - Du sagst es. Ich bins. -" erscheint auch im Dialog des verklagten Jesus mit dem Hohen Priester ("Kaiphas"). Wolfskehl bezieht sich hier auf die synoptischen Evangelien, vor allem die lukanische Überlieferung, die mit dem Wortlaut seiner Gedichterwiderung "Du sagst es. Ich bin's" beinahe wörtlich übereinstimmt ${ }^{37}$. Das alttestamentarische und neutestamentarische Geschichtsengagement Gottes steht bei Wolfskehls also gleichermaßen auch im Zeichen eines (jurististischen) Prozesses und einer Opferhandlung.

In der zahlenmystisch für Juden und Christen gleichermaßen bedeutsamen zwölften Strophe ("BIST DU Davids Reis und stehest in/Unserm Buche mitten drin?") 38 , wird die Frage nach dem $\mathrm{Zu}-$ sammenhang von christlicher und jüdischer Messianik aufgeworfen. $\mathrm{Da} \beta$ die Menschenstimme im Gedicht nicht nur als die eines Individuums verstanden werden kann, sondern auch auf eine kollektive (symbolische) Figuration hin deutbar ist, wird in dieser Tafel deutlich, da die Frage nach der Schriftoffenbarung des Messias aus der Perspektive der pluralischen jüdischen Buchgemeinschaft gestellt wird ("...in/Unserem Buche..."). Die Antwort der göttlichen Stimme ändert sich hier gegenüber dem vorherigen Synhedrions-Zitat, es heißt nun " - Dir tagt es. Ich Bins. -" Dem Frager wird also eine Erkenntniserweiterung (vom lediglichen Sagen, Aussagen, Hersagen, mit der Möglichkeit der Projektion) zum Verstehen (aufdämmern, "tagen") zuteil. Der Messias steht in Davidischer Sukzesson, ist also jüdisch. Und die Selbstqualifizierung Gottes wird im Verb erstmals kapitalisiert: "Ich Bins". Wichtig hier ist, daß der neutestamentarische Messias, Jesus, nicht die Vollendung oder Überwindung des Alten Testaments ist, sondern sein

37 Geht man von der Lutherübersetzung aus, auf die sich Wolfskehl bei seinen Zitaten und Paraphrasen des NT wesentlich stützt.

38 GW I, S. 196 (Hervorhebung N.P.F.). 
Zentrum. Aus dem jüdischen Buch, der jüdischen Schriftkultur, geht er hervor und bleibt dessen Mitte ("stehest... mitten drin"). Hier mag auch Georgeische Wortmystik Pate gestanden haben, denn George meinte, alles was die inspirierten Dichter und Propheten gesagt hätten, sei immer in Erfüllung gegangen. Hiermit verbindet sich die wissenschaftliche Erkenntnis der jüdischen und christlichen Leben-Jesu-Forschung, daß der empirische Jesus historisch, soziologisch und theologie-geschichtlich aufs engste mit seiner jüdischen Umgebung verbunden war, aus ihrer Mitte stammt, und daß seine Verkündigung sich auf jüdische Poetik und Prophetik bezieht.

In der Schlußstrophe wird die Messias-Stimme einen weiteren Schritt erhöht, nämlich in der Endzeile der Zweiten Tafel, der einzigen im gesamten Gedicht, die vollständig in kapitalen Lettern geschrieben ist und damit auf die maximale Heiligkeit von Stimme und Aussage verweist: “ - ICH BIN. ICH BIN. ICH BIN." Diese Zentralaussage bildet die Mitte des ganzen Gedichts. Das Pronomen "es" fehlt hier, die göttliche Stimme ist nicht mehr etwas Bestimmtes, pronominal objektiviertes, also z. B. ihre Emanation als jesuanischer Messias, sondern sie gibt sich als Absolutum zu erkennen. Sie ist die Selbstbezeichnung JHWHs, dessen hebräische Namensoffenbarung (2. Mose $3.14 \mathrm{ff}$.) "ehje ascher ehje" auf dem ontologischen Verb "sein" basiert, und traditionell eben als "Ich bin der ich bin" oder "Ich werde sein" (Luther) verdeutscht worden ist. Damit ist auch das kabbalistische En Sof Prinzips bezeichnet, der nach kabbalistscher Mystik höchsten und umfassenden Existenzweise Gottes. In der Schlußstrophe der Zweiten Tafel ist der christliche Universalanspruch des Johanneischen Logos-Christos, des änonischen Alpha und Omega ("Du Wort, Du Wesung, End Du, Beginn!"), sowie die johanneische Ego-eimiTheologie (Ich bin das Waser des Lebens, Ich bin das Licht der Welt, Ich bin der Weg und die Wahrheit, etc.) ebenfalls mit einbegriffen. Bemerkenswert ist in diesem Kontext die dreimalige - an christliche Trinität und Erlösungstrias (Paradies, Sündenfall, Erlösung) erinnernde - Wiederholung des "ICH BIN"; sie korrespondiert mit der dreimalig großgeschriebenen Frage im Text "BIST DU"39, diese steht in der ersten, der Paradiesfrage (Strophe 1), sodann in der Davidsfrage (12) und schließlich in der Peccata mundi Frage (16) der Zweiten Tafel; der jahwistische Gott wäre damit so-

39 Friedrich Voit verdanke ich den Hinweis, daß diese Großschreibung höchstwahrscheinlich von Margot Ruben für die Druckfassung der Gesammelten Dichtungen vorgenommen wurde; in den Manuskripten findet sie sich nicht. 
wohl in der Urgeschichte als auch in jüdisch-christlicher Heilsgeschichte anwesend. Und zwar wiederum gleichermaßen anwesend.

Nicht mehr das jesuanische, an die Kaiphas- und Pilatusfragen gemahnende "Ich bins", sondern das jahwistische " - ICH BIN. ICH BIN. ICH BIN" hat in dieser Tafel das letzte Wort. Daß beide in einer Art hypostatischer Union zusammenhängen, wurde oben schon angedeutet. Man kann hier auch eine Art dialogische Umkehrung ausmachen. Die alttestamentarischen Fragen beantwortet eine Jesus-Stimme, die neutestamentarischen die Stimme JHWHs. Somit wird die Verbundenheit und die Durchdringung dieser beiden heils- und überlieferungsgeschichtlichen Bereiche aufs nachhaltigste betont: Die jesuanische Messianik ist der Thora eingeschrieben (Strophen 1-12); JHWH- und En- Sof-Traditionen sind im Messiasgeschehen am Ende der Zweiten Tafel verankert.

Ein Bekenntnis zur christlichen Soteriologie erfolgt jedoch weder in der Zweiten Tafel noch irgendwo sonst in Wolfskehls "INRI"Zyklus. Der jesuanische Messias ist eine, wenn auch vielleicht die bedeutendste eschatologische Emanation des jüdischen Gottes JHWH. Er ist vor allem ein religiöser Messias, der als "Neues Lamm" (Strophe 17) ein göttliches Opfer in der Tradition des Gottesknechtes ist. Er ist hingegen kein Überwinder des Todes (ein wichtiges traditionelles Messiasattribut der jüdischen Tradition und die Zentralstelle nachösterlich-paulinischer Theologie) ${ }^{40}$, er bringt (noch) kein universales Friedensreich, er entbehrt der pluralischen Messianität und er ist keinesfalls der Vollender politischer Messianik, der das Gottesreich aufrichtet.

In der zentralen Endstrophe der Zweiten Tafel verbirgt sich aber noch eine andere religiöse Tradition, die sowohl jüdischen als auch christlichen Interpreten hybrid vorkommen mag. Es ist dies der Verweis auf die Religiosität des George-Kreises und seinen Kultstifter und kultischen Mittelpunkt Stefan George, welcher sich in einem seiner "Maximin"-Gedichte - unter Verwendung christlicher Trinitätsmystik - gern selbst als Vater-Figur seines "Neuen Gottes" Maximin geriert. Daß die Teilhabe am Georgeischen "Sein", seinem poetisch-eucharistischen Kult, von seinen "Jüngern" als Gott-Nähe, sinnstiftende und erlösende Gnade gedeutet wurde, ist mehrfach bezeugt. 41

40 Vgl. Goldmann, Alain, 'Die messianische Vision im rabbinischen Judentum'. (In: Stegemann, Ekkehard (Hrsg.), Messias-Vorstellungen bei Juden und Christen, Stuttgart, Berlin, Köln 1993, S. 62 ff.

$41 \mathrm{Vgl}$. Braungarts Ausführungen dazu sowie die Zitate von Wolters und Gundolf (nach seiner Trennung von George: "über allem Einzelnen schwebt die Angst... 
Georges Gedicht "Ich bin der Eine und bin Beide" aus "Der Stern des Bundes" endet mit den Zeilen: "Ich bin ein end und ein beginn." 42 Hier findet sich eine beinahe wörtliche Übereinstimmung zu Wolfskehls Huldigung an den äonischen Messias ("Du Wort, du Wesung, Ende Du, Beginn!"). ${ }^{43}$ Aber die Parallele zum George-Gedicht geht noch weiter: Dem dreifachen "ICH BIN" in Wolfskehls "INRI" korrespondiert der Parallelismus von Georges Zeilenanfänge: "Ich bin der Eine.../Ich bin der zeuger.../ Ich bin der degen..." usw. Sollte in Wolfskehls Jubelruf auf den äonischen Messias und in seinem Bekenntnis zu dem "ICH BIN" JHWHs auch eine Anspielung auf zentrale Passagen von Georges eigener poetischer Religionsstiftung enthalten sein? Man geht wohl nicht fehl, wenn man in dem religiösen Spitzensatz des treuen Gefolgsmannes, des Freundes und "Trabanten" des "Meisters" George 44 eine Synthetisierung aus Elementen jüdischer, christlicher und Georgeischer Gotteslehre sieht. George ist Wolfskehls höchstem Gott mit eingeschrieben.

\subsection{Dritte Tafel}

Die dritte ist die einzige Tafel im gesamten Gedicht, in der ein Dialog zwischen göttlicher und menschlicher Stimme nicht zustande kommt, in der die göttliche "vox" keine Antwort auf die Frage des lyrischen Ich spricht. So zeigt der Dichter bereits auf der Ebene der dialogischen Realisierung des Textes, daß die Kommunikation zwischen Ich und Messias - der hier am stärksten in christlicher Tradition beschrieben wīi - nicht zustande kommt; ebensowenig wie die in den Strophen drei und vier angesprochene (eucharistische) Verbindung erfolgt.

In dieser Tafel weicht die Dialogizität einem Fragemonolog, der in den ersten sieben Strophen eine Selbstanalyse in Form einer Selbstbefragung enthält, bevor ein jesuanisch-christlicher Messias angesprochen wird. Dieser wird in der ersten Strophe bereits mit "Heilsherr" bezeichnet, einem Ausdruck, welcher dem alten deutschen "Heiland" nahekommt, der Wolfskehl als Mediävist selbst-

mit meinem Gott nicht eins zu sein", S. 233). In: Braungart, Wolfgang, Ästhetischer Katholizismus. Rituale der Literatur, Tübingen 1997. Besonders wichtig in diesem Zusammenhang die Kapitel "liturgische Lyrik" und "Poetische Eucharistie".

42 SW, Bd. VIII., S. 27.

43 GW I, S. 197.

44 Zum Verhältnis von Wolfskehl und George vergl. Schlösser I. Darin vor allem das Kapitel "Karl Wolfskehl und Stefan George", S. 70 ff. 
verständlich geläufig war, und welcher der kirchlichen Vorstellung eines messianischen Christus konzeptionell vor allen anderen Passagen im Gedichtzyklus am nächsten kommt. Diese Nähe zum christlichen Messiasverständnis wird noch unterstützt durch die diversen Anspielung auf die Evangelienüberlieferung.45 Der Leitgedanke der Dritten Tafel, nämlich die Frage der Erwählung zur Messiasgemeinschaft oder - christlich ausgedrückt - die Heilserwählung zum Glauben an Christus und damit zur Kirche Christi als Gemeinschaft der Heiligen, zeigt die größtmögliche Annäherung des Autors an die Begriffs- und Glaubenswelt christlicher Erlösungslehre. Er zeigt aber sogleich auch den Punkt, an dem Wolfskehl dem Christentum nicht folgen kann.

Das öffentliche poetische In-sich-gehen des Gedichtsubjektes als Fragendem ist aus der pietistischen Erbauungsliteratur ebenso bekannt wie aus ihren romantischen Adaptionen. ${ }^{46}$ So begegnet man in den "Geistlichen Liedern" Friedrich von Hardenbergs (Novalis) strukturell erstaunlich. ähnlichen Äußerungen einer suchenden "Seele" wie in Wolfskehls "INRI"-Zyklus. Daß Wolfskehl Novalis' Werke genauestens gekannt hat, ist allein schon daraus ersichtlich, daß er die Werke des Frühromantikers in der Münchner Rupprechtspresse herausgegeben hat. ${ }^{47} \mathrm{Im}$ XI. Geistlichen Lied des Novalis etwa wird die strukturelle Parallele der Frageassonanzen zu Wolfskehls Gedicht besonders deutlich, so in den Strophen 5 und 6 ("Hat er sich euch nicht kundgegeben?//Habt ihr von ihm denn nichts gelesen?")48 Novalis' Strophen drücken jedoch einen Verkündigungsgestus aus und seine lyrischen Fragen sind wenigstens für die bereits Glaubenden Suggestivfragen. Für Wolfskehls Gedichtsubjekt ist Selbstbefragung Selbstverständigung, Lamento, aber auch Ausdruck der Trauer darüber, daß es trotz intensiver Bemühungen dem christlichen Gott - auch in seiner Kirche - nicht wirklich begegnet ist.

Die vierzehnte Strophe paraphrasiert die neutestamentarische Eckstein-Perikope. Die Eckstein-Perikope bezieht Wolfskehls lyrisches

$45 \mathrm{Zu}$ beachten ist selbst hier allerdings wiederum ihre Verbindung mit der Thora-Überlieferung.

46 Es sei an dieser Stelle auch auf die besondere Bedeutung eines anderen Romantikers, Clemens von Brentano, für Wolfskehl hingewiesen. Diesen Hinweis verdanke ich Paul Hoffmann.

47 Die mystischen Gedichte des Novalis. Zusammengestellt und herausgegeben von Karl Wolfskehl. München 1922 (als 17. Bd. der Rupprechtspresse).

48 Novalis, Schriften. Bd. I. Das dichterische Werk. Hrsg. v. Paul Kluckhohn und Richard Samuel, Stuttgart 1960, S. 172. 
Ich eigenartigerweise unmittelbar auf sich selbst, und zwar in dem Sinne, daß das Ich selber zu einem Baustein, wenn nicht gar Eckstein ${ }^{49}$ des Heilsgebäudes werden möchte. Dieser Sachverhalt verdient zusammen mit der letzten, der fünfzehnten Strophe besondere Beachtung.

Die Schlußtrophe der "R"-Tafel verfügt über acht Zeilen, nach einer gematrischen Lesart Zahl des Verhängnisses. In ihr fragt das lyrische Ich den Messias wiederholt, warum er den Frager nicht angenommen habe ("Hast Du mich nimmer wollen...?").50 Das Reflexivpronomen "mich" erscheint in dieser Strophe ebenfalls achtmal und dominiert deshalb auch die Klanggestalt der Passage.51 In dieser Strophe wird die Tragik der Messias-Distanz noch einmal ganz ins Individuelle des Fragenden gewendet. Es scheint hier, als wäre es das selbstverkrümmte Vordrängen des Individuums, welches den Kontakt zum Messias versperrt. Und mehr noch: In den Schlußstrophen scheint ein Element von selbstüberheblichem Automessianismus auf: das lyrische Ich hat selber Ambitionen, zum messianischen Eckstein zu werden. Diese Hybris, so scheint es, büßt es durch Gottes Schweigen.

\subsection{Vierte Tafel " "}

In der Vierten Tafel wird die Dialogizität zwischen göttlicher und menschlicher Stimme wieder aufgenommen, jedoch nicht in Wechselrede, sondern in zwei Textblöcken. Durch die explizite Bezeichnung der göttlichen Stimme als "vox" hat diese Tafel die größte Ähnlichkeit mit dem dialogisch ähnlich gestalteten Gedichtband "Die Stimme spricht".

In der Vierten Tafel spricht die "vox", die messianische Emanation JHWHs, als jesusanische, denn sie verweist das menschliche

$49 \mathrm{Ob}$ das lyrische Ich tatsächlich der Eckstein oder nur ein Bauelement werden möchte, ist syntaktisch nicht eindeutig.

50 GWI, S. 199.

51 Beim lauten Lesen des Textes wird die Aufdringlichkeit der Häufung der "mich" Stellen deutlich, da beim Reziteren das Phonem "ich" besonders hervorsticht. Die klangliche Gestalt des Reflexiypronomens für die 1. Person Sg. betont die Autoreferenz, die Rückwendung oder -krümmung auf den Sprechenden. Seine Selbstverlorenheit wird durch das Verb "verwirken" und die Präposition 'in' ("verwirkt in mich") noch betont. Der Sprecher ist hier nicht mehr als mögliches Subjekt am Heilgeschehen beteiligt oder durch die prädikative Struktur des Gottesnamens (vgl. die Zweite Tafel) in das Wirken Gottes einbezogen, sondern er erscheint entpersönlicht und gottverlassen in seiner Selbstverhaftetheit. In der Begierde zur Apotheose wird der Mensch hier in seiner Selbstbezüglichkeit schließlich zum Gefangenen seiner selbst. 
Fragesubjekt deutlich auf alttestamentarische Zusammenhänge, in welchen JHWH in der dritten Person angesprochen wird. Aus der Tatsache, daß diese jesuanische "vox" dem menschlichen Frager zu seinen Fragen hinsichtlich von Metaphysik, Mystik und (Auto-) Messianismus Rede steht, ist zweierlei Bemerkenswertes abzulesen. Erstens spricht die jesuanische Stimme den Fragenden dezidiert als jüdischen Frager an, indem auf Thora-Erzählungen verwiesen wird, in der die alttestamentarischen Charaktere auch in traditioneller Schreibweise ("Abram", "Moscheh") aufgerufen werden. Jesu Stimme spricht hier direkt mit einem jüdischen Frager - und es ist nicht etwa eine Paraphrasierung der synoptischen Evangelien oder paulinischer Apostolik, mittels derer der eschatologische Status der Juden bestimmt wird. Die jahwistisch-jesuanische Stimme verweist das Fragesubjekt auf den Alten Bund und suspendiert es damit indirekt vom Neuen. Doch in der dialogischen Sprache, in der unmittelbaren Ansprache des Fragenden durch die göttliche Stimme besteht seine Anerkennung, ja seine Rechtfertigung, obwohl er an der direkten Kommunion der christlichen Heilsgemeinschaft nicht teilnehmen kann ("Nicht Brot, nicht Wein//Mag dir gedeihn"). Hierin zeigt sich eine Parallele zum Bibliodrama des Hiob-Buches. Hiobs "Rechtfertigung" besteht ja gerade nicht primär in den kosmologischen und metaphyischen Erklärungen Gottes, welche ohnehin den menschlichen Verstand übersteigen, und auch nicht in der Restauration des Dulders am Ende der Erzählung, sondern in dem Akt der Zuwendung Gottes, der Tatsache also, daß Hiobs existentielle Frage von Gott selbst ernstgenommen wird. So auch in der letzten Tafel von Wolfskehls "INRI"-Zyklus: Die eigentliche Proposition der jesuanischen Stimme bleibt apokalyptisch dunkel, die Problematik der Erwählung des Fragenden und seine Zuweisung an den Alten Bund bleiben weithin unbestimmt ("ER weiß warum") - vielmehr ist es die Tatsache, daß ihm die Stimme des Messias, welcher zugleich eine Emanation JHWHs ist, spricht, welche die grundsätzliche Bestätigung des Fragers ausdrückt. Dieses aber leistet wesentlich die Dialogstruktur des Textes.

Inhaltlich wird in dieser Tafel die Problematik der menschlichen Mitwirkung am eschatologischen Geschehen angesprochen. Das menschliche Fragesubjekt (mit einem wohl erheblichen Anteil ihres Autors) will wissen, ob mit ihm "das Geviert" schließt und "das Leid die Not" verliert, indem eine mystische Endzeitdynamik freigesetzt wird, in der "Verheißung und Gebot", "Reich und Zeit" zusammenfallen. Diese Anfrage findet am "offenen Tor" statt. 
Das Tormotiv ("Am offnen Tor/Am baren Tor")52 verweist sowohl auf einen möglichen Durch-, bzw. Übergang zu dem Messias ("Am offnen Tor") als auch auf eine Gerichtssituation ("Am baren Tor"). Da die Torgerichtsbarkeit im alten Israel oft eine Halsgerichtsbarkeit war, wäre die Konfrontation des lyrischen Ich mit dem Tor in dieser Lesart eine existentiell wichtige, die Frage nach dem Messias am Tor also eine auf Leben und Tod. So steht das lyrische Ich vor einer existentiellen Entscheidung und ist ganz dem Richter- oder Zuspruch der göttlichen "vox" ausgeliefert. 53

Ob der Dichter sich hier auch als Vollendeter der - in jüdischer und christlicher Tradition heilig gehaltenen - Vierzahl, etwa von vier Relgionskreisen (jüdisch, griechisch, christlich, Georgeisch?) ansieht, muß offenbleiben. Entscheidend ist, daß die menschliche Fragestimme nicht an der Vollendung der messianischen Erlösung durch mystische Kommunion teilhaben kann. Die jüdischchristliche Offenbarungsmystik (Zusammenfall von Verheiß und Gebot), die eucharistische Mystik von Brot und Wein und die Reichsmystik (Zusammenfall von Zeit und Reich), letztere sowohl in christlicher (he basilea tou theou) als auch in Georgeischer (Geheimes Deutschland) Bestimmung, können den Zustand zu vollendeter Gemeinschaft mit Gott für das lyrische Sujekt Wolfskehls nicht herstellen. Die göttliche Stimme verweist den Frager von der Mystik an die jüdische Geschichte und an die Mythologie zurück. Das menschliche Subjekt wird in der Vierten Tafel übrigens auch dezidiert als kollektives Subjekt ("Israel”) identifiziert:

Du rangst und rangst
Mit Urnachtangst,
dann ward es hell,
Ward Israel. ${ }^{54}$

52 GW I, S. 200.

53 Unter den zwölf geistlichen hebräischen Dichtungen, die Karl Wolfskehl zwischen 1935 und 1938 ins Deutsche übertrug (Vorabdrucke im Schocken Almanach), befindet sich ein Gedicht Schlomoh Ibn Gabirols "Schon schloß das Tor", daß auf Motiven des Hohen Liedes beruht. Möglicherweise ist das "bare Tor" des INRI-Zyklus ein geschlossenes Tor (vgl. Wölfskehls Verwendung des Adjektives "bar" in anderen Kontexten). Dann hätten wir hier vielleicht eine Parallele zum Gedicht des sephardischen Mystikers vorliegen. Interpretierte man das lyrische Ich des "INRI"-Gedichts als kollektives Israel wäre es - jedenfalls in der Vierten Tafel - auch in der Tradition der Ahawa, einer religiösen Dichtungsform, welche die Liebe zwischen Gott und Israel zum Thema hat, zu sehen. 
Eine abschließende Antwort über das Warum der verschiedenen Wege jüdischer und christlicher Heilsgeschichte gibt die göttliche "vox" nicht ("Ich vor dir stumm,/ich deiner Frag"), sie gibt auch keinen Aufschluß über den konkreten Verlauf der eschatologischen Ereignisse bis zum Ende der Geschichte. Dieses Ende wird in der zwölften, der Schlußstrophe in der Tradition jüdischer und christlicher Apokalyptik allerdings angekündigt. Es steht im Zeichen des Schwellenerlebnisses (des krähenden Hahns), und des offenbarenden Endgerichts ("Posaunenschlag"). Es offenbart den gesamten eschatologischen Heilsrahmen Gottes, der die Kosmologie, die mythische wie empirische Geschichte einschließt ("Aufreisst der Plan"). Zugleich verbirgt sich in diesem Schlußwort wiederum eine Anspielung auf die im George-Kries umlaufende Reichsmystik des Geheimen Deutschland, in dem die antike und mittelalterliche Unterscheidung von Imperium und Sacerdotium aufgehoben sein soll.55

\section{Situierung des "INRI" Zyklus innerhalb der Exildichtung}

Es besteht kein Zweifel, daß Wolfskehl seine Exildichtung als kompositionelle Einheit gestalten und dies auch in ihrer Veröffentlichung berücksichtigt sehen wollte. In den Anmerkungen zu den Gesammelten Dichtungen heißt es, daß er in den Jahren 1946 und 1947 intensiv an der endgültigen Kanonisierung und Gruppierung der Texte für eine avisierte Ausgabe letzter Hand gearbeitet habe. 56 Als Kernbestandteile einer Sammlung von Exilgedichten galten wohl zunächst "Mittelmeer" und "Hiob". Bald darauf spricht Wolfskehl von "einem Buch, gerade zu Ende gebracht, drei Zyklen - die Drei Welten, aus denen meine geistige Gestalt erwuchs. Dem zugefügt das Gedicht An die Deutschen."57 Die Gesamtplanung findet sich in einer Diarien-Notiz vom Dezember 1946:

54 GW I, S. 201 Jacob-Israel ist in Genesis 32, 23 ff. zunächst der Erzvater, dessen Ehrenname Israel dann aber auf Stamm und Volk übergeht, also kollektiviert wird.

55 Vergl. Georges Gedicht "Die Gräber in Speier", mit seinem Hinweis auf den "Karlen- und Ottonenplan" sowie den staufischen Plan eines Universalreiches, die ein sowohl geographisches als auch historisches und geistesgeschichtliches Szenario bezeichnen.

56 GW II, S. 570.

57 GW II, S. 570. 


\section{Die Drei Welten: \\ Mittelmeer oder die Fünf Fenster \\ INRI oder die Vier Tafeln \\ Hiob oder die Vier Spiegel}

II. Das Lebenslied:

Heimat: An die Deutschen

Bann: Hinfahrt und weitere Einzelgedichte ${ }^{58}$

Obwohl Wolfskehl bis kurz vor seinem Lebensende den Wortlaut einzelner Gedichte und Umfang und Reihenfolge innerhalb der geplanten Werk-Ausgabe veränderte, ist diese Notiz doch als maßgebend anzusehen.

Innerhalb der Großzyklen der "Drei Welten" bildet "INRI" das symmetrische Zentrum. Man kann die drei Werke aber auch gleichsam final betrachten: Schluß- und Höhepunkt wäre dann der "Hiob"-Zyklus. Im Sinne einer Bedeutungsperspektive spricht vieles für letztere Lesart. Denn im "Hiob"-Zyklus entwickelt Wolfskehl all jene messianischen Vorstellungen, die im "INRI" noch unabgegolten sind. Dazu gehört die Vorstellung vom kollektiven Messisas (im "Hiob Israel"), vom prophetisch-politischen Messias (im "Hiob Nabi") und schließlich von der vollständigen und konkreten Identifizierung von Gottesknecht und Messias (im "Hiob-Maschiach"), der menschlich ergreifensten Ausformung des Wolfskehlschen Messianismus, Schlußwort auch seiner Dialogizität mit Gott.59 Anspielungen an Georgeische Religiosität sind im "Hiob" völlig getilgt. Nicht so jedoch die Verbindung mit der jesuanischen (und christlichen) Messiasvorstellung aus dem "INRI". Dies zeigt sich an dem Vorspruch des "Hiob"-Gedichts. Dort heißt es:

Tränen sind der Seele herber Wein,

Fliessend aus des Leids uralter Trotte.

Lauter dann, von Erdentrübe rein,

Glänzt der Wein, heissts, Spiegel Unserm Gotte.

$[\ldots]$

58 GW II, S. 570.

59 Vgl. hierzu auch den Beitrag von Norman Simms in dieser Sammlung sowie meinen Essay "Job or the Four Mirrors: An Interpretation of Karl Wolfskehl's last poetical Cycle". In: Simms, Norman (Hrsg.), Sects, Sex and Identity, Hamilton 1997. 
Dass er kühl in deinen Kellern gärt!

In der grossen Flut gönn eigenen Tiegel

Meinem Wein, Leid, bis er, ausgeklärt,

Ganz demanten, wert ist Gottes Spiegel.60

In diesem mit Anspielungen an jüdische und christliche Weinmetaphorik gesättigten Gebet, in dem Wolfskehls lyrisches Ich bittet, daß sich sein Lebensschicksal, seine intellektuelle und religiöse Erfahrung zu bleibender Form läutere, um Gottes Spiegel zu sein, verbirgt sich die Erinnerung an einen christlichen Text des mittelalterlichen Archipoeta, den Wolfskehl übersetzt hatte, und dem er das Motiv des Tränenweins verdankt. Bezeichnenderweise entstammt sie den Archipoeta-Strophen über den am Kreuz leidenden Heiland:

Wenn am Kreuz der Schöpfer das Leiden spürt, Muss von Stahl sein, wer kein Mitleiden spürt. Wenn der Heiland Stiche der Lanze spürt,

Muss von Stein sein, wer nicht die Lanze spürt.

Lasst die Lanze dringen ins Herz hinein, Gottes Zorn macht gut mit der Tränen Wein.

Tag des Zornes, spätesten Tages Schein

Naht sich eilig, wehe, bald wird er sein. ${ }^{61}$

Dem für Wolfskehls Theologie bedeutendsten Zyklus, dem "Hiob", in welchem er sein eigenes Gottesknechtslied ("Hiob Maschiach") anstimmt, steht also eine Anspielung an den leidenden Gottesknecht der christlichen Messianik voran, in der auch der apokalyptische Ton der letzten "INRI" Tafel anklingt. Das Motiv der mimetischen Nachfolge im Leid und der göttlichen Buße im Tränenwein verbindet Wolfskehls jesuanisch-christliche und seine jüdische Messianik.

60 GW I, S. 203.

$61 \mathrm{GW}$ II, S. 70. 